\title{
JRC2009-63009
}

\section{EVALUATION OF RAIL TEST FREQUENCIES USING RISK ANALYSIS}

\author{
D.Y. Jeong \\ J.E. Gordon \\ Volpe National Transportation Systems Center \\ U.S Department of Transportation \\ Cambridge, Massachusetts, USA
}

\begin{abstract}
Several industries now use risk analysis to develop inspection programs to ensure acceptable mechanical integrity and reliability. These industries include nuclear and electric power generation, oil refining, gas processing, onshore and offshore exploration and production, chemical processing, and pipelines. Risk analysis may also be used as a decisionmaking tool in the railroad industry to develop systematic improvements in track maintenance and inspection strategies.

In the course of conducting research in support of the Federal Railroad Administration, a Monte Carlo risk assessment model has been developed to simulate certain aspects of rail inspection (also referred to as rail testing) to find and remove defects that may grow to sufficient size to cause rail failures. In this paper, the model is used to examine the relationship between the occurrence of rail failures and various operational factors. These operational factors include rail size, average axle loading, and inspection frequency. In addition, the risk assessment model is used to evaluate an alternative rail testing concept in which detector cars would conduct inspections at speeds higher than those used in current practice.
\end{abstract}

\section{INTRODUCTION}

Rail failures, or broken rails, generally occur from fatigue cracks or defects that form and grow in the rail steel as a result of cyclic forces caused by the repeated passage of trains over the rails. Moreover, a broken rail may cause a train to derail.

The primary means of controlling the risk of rail failures is rail testing. Rail testing is the continuous search of rail to find defects, in order to allow time for remedial actions to occur prior to rail failures. Remedial actions may entail protection or repair of discovered defects, removal of defective rails from track, or a temporary restriction on train speed. The search for surface-breaking rail defects can be performed visually, but the search for internal defects must be performed with specialized equipment using ultrasonic or magnetic induction technology. Moreover, safety is maintained by scheduling rail tests frequently enough to ensure that defects are discovered and removed before they grow large enough to cause rail failure.

Scheduling the frequency of rail tests is a complex and challenging task involving many interacting and competing factors. For example, scheduling rail tests requires prudent allocation of available resources during limited availability of track time between trains running over the track and routine maintenance procedures. The task of scheduling rail tests is further complicated by the fact that rail defects can form and grow at different rates on different lines, or at different times on the same line. Consequently, scheduling of rail tests has evolved slowly in response to field experience. This evolutionary approach has worked well over time because contemporary conditions that affect rail performance have also changed slowly.

Research sponsored by the Federal Railroad Administration (FRA) has produced technical information on the behavior of rail defects [1]. With this knowledge, railroads in North America have begun to evolve their rail testing programs based on quantitative methods such as engineering fracture mechanics and statistical analysis to complement several decades of field experience. Moreover, research has reached a point where risk analysis may be used to develop effective maintenance and rail testing strategies to help improve safety.

Absolute safety of the track system cannot always be guaranteed due to uncertainties in system parameters. For instance, the process of rail testing is highly reliable but not perfect. Therefore, the only rational goal for a rail testing 
program is to limit the population of undetected defects to some tolerable level. A guide for scheduling the frequency of rail tests was developed with this thought in mind [2].

The guide was designed for self-adaptation to changing track conditions, as reflected by the total rate of detect occurrence per test, the rate of service defect occurrences, and the tonnage of traffic accumulated between tests. Service defects are defects found by means other than scheduled tests (e.g., when a rail breaks under a moving train). Selfadaptation means that the frequency of rail testing is adjusted according to the observed rate of service defects. Moreover, the guide calculates the frequency of rail tests required to maintain the service defect rate at a level that is equal to or less than an acceptable or tolerable level of risk.

The likelihood of unacceptable performance can be limited to a reasonable level with effective management strategies. This likelihood can be estimated using risk analysis.

In the course of conducting research in support of the FRA, the Volpe National Transportation Systems Center (Volpe Center) has developed a risk assessment model to simulate certain aspects of rail testing on a hypothetical railroad subdivision [3]. In this model, risk is quantified in terms of the occurrence of service defects. The model uses the Monte Carlo method to simulate the rail defect formation and growth caused by traffic, together with the effect of periodic inspections on the defect population, on a hypothetical, single-track line along which the rail age is assumed to be uniform. All defects are assumed to be internal rail defects called detail fractures, which are the most common internal rail defect found in continuous welded rail (CWR) carrying heavy freight traffic in North America.

The risk assessment model was originally applied to study the concept of delayed remedial action in comparison with current safety standard procedures that require immediate remedial action when a defect is detected. In principle, the benefits of the delayed action strategy would be an increase in the average number of track miles inspected per day by detector cars, which in turn could potentially lead to detection of more defects that would otherwise be expected to cause rail failures.

In this paper, the risk assessment model is applied to examine the relation between the risk of rail failures and operational characteristics. Specifically, the model is used to examine the changes in detected and service defects as rail size and axle loads are varied. Moreover, the risk model can also be used to estimate the frequency of conducting rail tests to mitigate the occurrence of service defects. In addition, the risk assessment model is used to evaluate a concept of highspeed rail testing in which detector cars would conduct rail tests at speeds greater than those conducted under current speeds, which are about 10 to 15 miles per hour (mph).

\section{MONTE CARLO SIMULATION MODEL}

The simulation is performed for a single-track subdivision of a specified length. The model assumes an arbitrary length of 1000 miles, which is based on numerical experiments, to assure stable averaging of Monte Carlo fluctuations [3]. The model comprises three major parts: (1) defect formation, (2) defect growth, and (3) defect detection and removal. Figure 1 shows a schematic of the Monte Carlo model. All defects are assumed to be detail fractures, with occurrence and growth rate characteristics modeled on the basis of prior research [1, 2]. The defect population is assigned by a whole number milepost. Rail size is assumed to be uniform for the entire subdivision. The initial rail age is also assumed to be uniform, and equal to 100 million gross tons (MGT), which is also based on numerical experiments [3].

The model is used to calculate the number of defects found from rail tests and the number of service defects on a line with a given annual tonnage and rail test frequencies. The model can also be used to evaluate inspection strategies in terms of the average number of track miles inspected by a detector car.

Tonnage is accumulated daily based on 1/365 of the assumed annual rate. The model calculates dates for: (a) the formation of defects at randomly assigned mileposts, and (b) the next inspection. Defects are removed from the simulation and counted as a detected defect when the defect is found by the detector car. Undetected defects are grown to the next significant date. Defects are removed as service defects if the size reaches 80 percent of the unworn rail head area (\%HA). The simulation is repeated ten times and averaged to smooth out fluctuations.

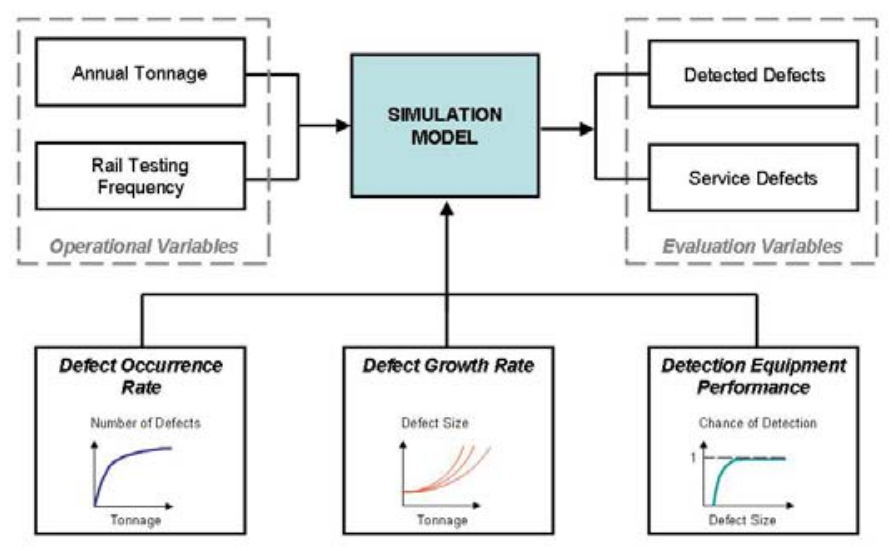

Figure 1: Schematic of Monte Carlo Model

\section{Defect Formation}

Defects are assumed to form at an increasing rate as the rail ages due to the accumulation of tonnage. The model for the rate of defect formation is based on statistical parameters derived from observations of defect occurrence on the Facility for Accelerated Service Testing (FAST) at the Transportation 
Test Center in Pueblo, Colorado and on several segments of revenue track studied by the Association of American Railroads [4]. Moreover, the data can be characterized by the Weibull distribution [5]:

$$
F(T)=1-\exp \left[-\left(\frac{T}{\beta}\right)^{3}\right]
$$

where $T$ is the rail age in cumulative MGT, $\beta$ is called the characteristic life, and $F(T)$ is the cumulative fraction of rails that have developed a defect by age $T$. The characteristic life depends on average axle loading. For example, $\beta$ is equal to 1,000 MGT on FAST and is equal to or greater than 1,500 MGT on freight revenue track. These parameters are based on data obtained from track with 39-foot rails. Rail generally reaches its economic life limit before the cumulative tonnage, $T$ exceeds the characteristic life. By definition, 63 percent of the rails will contain a defect when the rail age, $T$ is equal to the characteristic life, $\beta$.

\section{Defect Growth}

A simplified model of defect size progression was derived from engineering studies conducted by the Volpe Center on the growth rate of detail fractures [1]. This model was calibrated from the original detail fracture growth test conducted on tangent track at FAST $[6,7]$ and has been further verified and validated by comparison with results from additional experiments on curved track on the FAST High Tonnage Loop [8] and tests conducted through a joint international research effort supported by the Union of International Railways/World Executive Council [9, 10]. The growth rate model estimates size progression for specified conditions, which include temperature differential. The growth model is implemented into the Monte Carlo simulation in the form of an expected progression curve, given in terms of defect size (in \%HA) as a function of accumulated tonnage since defect occurrence. This characteristic is applied individually to update the size of each simulated defect as the rail ages through several years of simulated track usage and rail inspection.

After a defect is formed, it will grow under continued service. Each defect is assumed to have an initial crack size of about $0.5 \%$ HA. This value represents the smallest size which detail fracture growth curves were established by measurements of the exposed crack surface after an experiment on curved track at FAST [8]. The defect growth rate depends on several factors such as rail properties, axle load, weather, and other service conditions. Defects that grow to $80 \% \mathrm{HA}$ are assumed to cause rail failures.

Figure 2 illustrates the defect growth curves used in the Monte Carlo simulation model. These curves are simplified representations of detail fracture growth model results, which are intended to approximate the seasonal influence of thermal stress in CWR. The curve with the slowest growth rate represents rail at service temperatures within $\pm 5^{\circ} \mathrm{F}$ of the CWR neutral temperature, whereas the curve with the fastest rate represents rail at service temperatures from 10 to $35^{\circ} \mathrm{F}$ below the CWR neutral temperature. These bounding curves represent summer and winter conditions respectively. In the simulation model, defect growth per MGT is projected from a seasonally adjusted rate, based on one of the curves shown in the figure, for each calendar month.

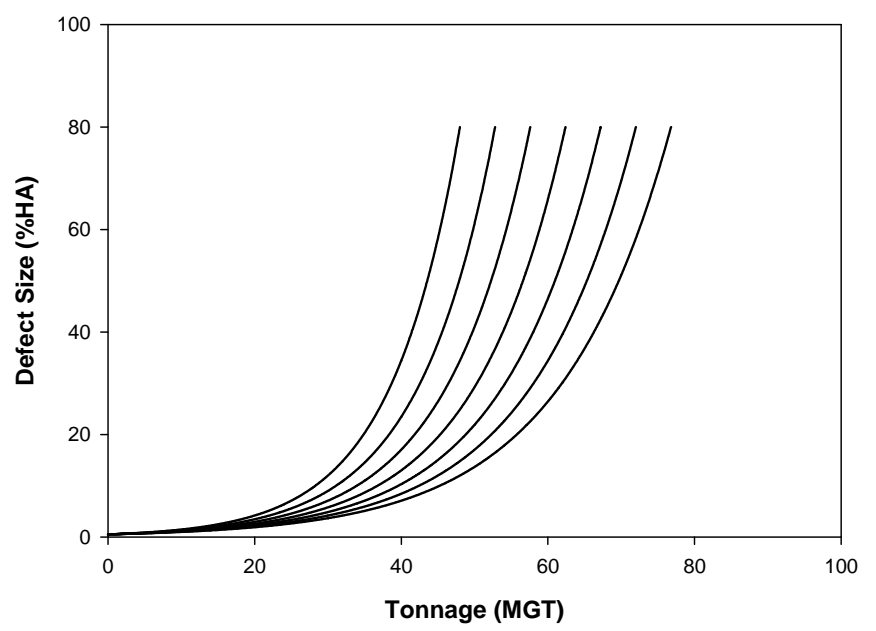

Figure 2: Detail Fracture Growth Curves with Varying Service Temperature

Once a defect has formed, the remaining useful life of the rail is characterized by the slow crack-growth life which is defined as the time or tonnage for a defect to grow from barely detectable size to the size at which rail failure is expected to occur (i.e., critical size). Moreover, the slow crack-growth life defines the window of opportunity to find the defect. Clearly, the maximum time or tonnage between rail tests should be equal to the slow crack-growth life in order to detect the defect before it grows to a critical size. Tonnage intervals that are less than the slow crack-growth life can provide more opportunities to detect the defect before it grows large enough to cause rail failure.

\section{Defect Detection and Removal}

Defect detection performance depends on the type of equipment used in rail tests. Although larger defects are more likely to be detected, they still can be missed during the inspection process. Defect detection performance is modeled in terms of detection probability, $p(s)$, as a function of defect size, $s$. Figure 3 is a schematic illustration of the curve, which is interpreted as follows. For a particular defect size, the curve gives a fractional number between zero and one which defines the chance of detecting defects of a given size. If $p(s)$ is equal to 0.1 , for example, then the expectation is that one out of ten defects of that size will be detected. 


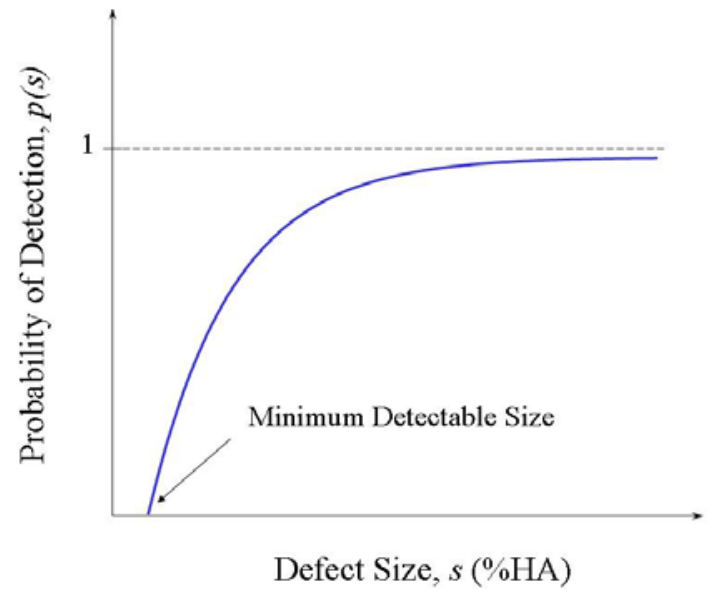

Figure 3: Schematic of Detection Probability Curve

It is impractical to obtain $p(s)$ by means of experiment because any test result would apply only to the specific combination of equipment, calibration procedures, operator experience, track, and weather conditions tested. In addition, $p(s)$ could not be obtained without an immediate supplemental inspection by a system of near-perfect detection capability to identify the defects missed by the test system, and breakage of rail samples containing the defects in order to establish their true sizes. Under these circumstances, the only practical approach is to infer $p(s)$, via a trial-and-error process, from the available statistics for overall system performance. During prior research, national statistics were fitted with a detection curve corresponding to older rail inspection equipment. The derived curve is given by [3]

$p(s)=1-\exp \left[-\left(\frac{s-5}{14}\right)\right]$

where $s$ is greater than or equal to $5 \% \mathrm{HA}$ (assumed as the minimum detectable size). This characteristic represents detection performance of ultrasonic systems equipped with a single $70^{\circ}$ sensor per probe wheel.

Each defect in each mile of the hypothetical track is checked for detection during each inspection. Detected defects are assumed to be removed from the track. Defects not detected are allowed to continue growing until the next inspection or until reaching $80 \% \mathrm{HA}$, which ever comes first. Defects that reach $80 \% \mathrm{HA}$ are counted as rail failures (service defects) and removed from the population.

No attempt is made to predict derailments, since analysis of railroad records has shown that only a small percentage of rail failures actually cause derailments. Most such rail failures are discovered by means of signal system indications, train crew reports, or track patrols, and are repaired. The total number of service defects is used as a relative, albeit indirect, measure of derailment risk.

\section{RESULTS}

In this paper, the risk assessment model for rail defect detection is used to study the effect of rail size and average axle load on the occurrence of service defects. In addition, the concept of high-speed rail testing is evaluated as a potential alternative rail testing strategy to current practice.

Results from the model are presented in terms of the service defect rate as a function of the detected defect rate. Here the defect rate is the number of defects per track mile per year. Moreover, risk (or benefit) is quantified in this paper as the increase (or decrease) in service defect occurrence rate.

The duration of the simulations in terms of the simulated number of years varied (typically, between three to ten years) depending on the particular hypothetical case. Moreover, the level of safety in terms of change in service defect occurrence rate was considered the most significant parameter of interest in this paper.

\section{Effect of Rail Size}

The risk assessment model is exercised to show the risks associated with changing rail size on a hypothetical railroad line from $132 \mathrm{RE}$ to $115 \mathrm{RE}$. Conversely, the results may also be interpreted as the benefits associated with changing the rail size from $115 \mathrm{RE}$ to $132 \mathrm{RE}$.

Figure 4 compares the defect growth curves assumed in the model for the two different rail sizes at $35^{\circ} \mathrm{F}$ below the CWR neutral temperature. That is, the defect-growth curve for $132 \mathrm{RE}$ rail in Figure 4 corresponds to the fastest growth curve or left-most curve in Figure 2. Figure 4 indicates that the slow crack-growth life of detail fractures in $115 \mathrm{RE}$ rail is about 29 percent less than that in $132 \mathrm{RE}$. The reduction in slow crack-growth life for $115 \mathrm{RE}$ is consistent with the fact that bending stresses are increased due to the smaller section properties (i.e., bending moments of inertia and crosssectional area) which in turn increase the rate of defect growth and shorten the overall fatigue life.

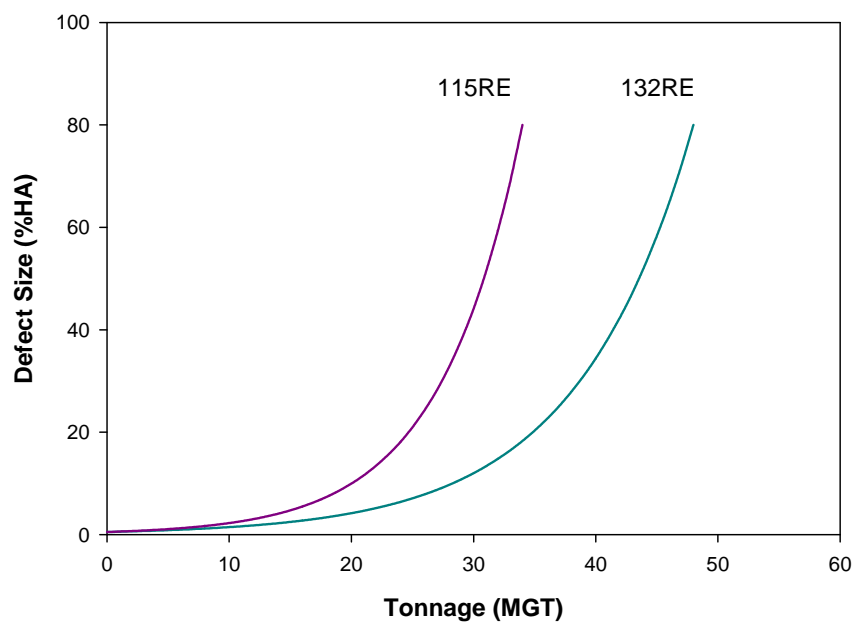

Figure 4: Defect-Growth Curves for Different Rail Sizes 
In the present application of the risk model, the rate of defect formation (i.e., crack initiation) is assumed to be independent of rail size. That is, only the defect growth rate is affected by changing rail size. Some defects, such as rolling contact fatigue cracks, form and grow due to wheel/rail contact stresses and residual stresses, which are not significantly affected by rail size. Therefore, the rate of defect formation does not appear to be significantly affected by rail size.

Figure 5 shows the results from the Monte Carlo model for this hypothetical example in which the traffic density is assumed to be 60 MGT per year while the frequency of rail testing is varied. Specifically, two different rail testing intervals (twice per year and three times per year) were assumed for the two different rail sizes. Thus, Figure 5 shows model results from four different cases. In each case, the service defect rate increases somewhat linearly as the detected defect rate increases. For the same rail size, the slopes of these curves are greater for two tests per year than those for three tests per year. The slopes of these curves appear to define levels of safety in terms of risk from service and detected defects. Moreover, these results suggest that the risk can be mitigated by conducting rail tests more frequently. For example, conducting rail tests three times a year on the line with $115 \mathrm{RE}$ gives a level of safety that is slightly greater than inspecting $132 \mathrm{RE}$ rail twice a year. In other words, conducting rail tests every 20 MGT on a line with 115 RE rail results in slightly fewer service failures than conducting rail tests every $30 \mathrm{MGT}$ on a line with $132 \mathrm{RE}$ rail.

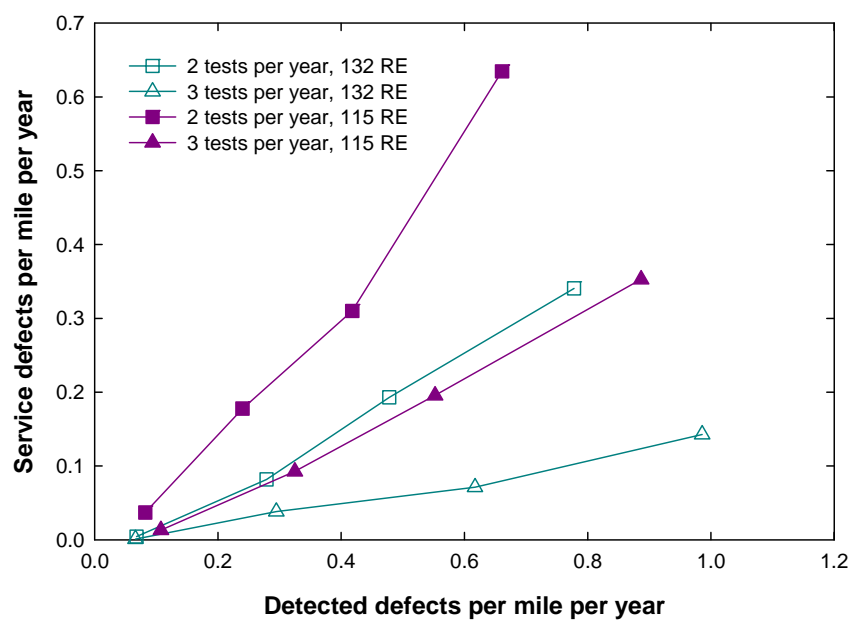

Figure 5: Effect of Rail Size and Inspection Frequency on Service Defect Rate

\section{Effect of Heavier Axle Loads}

The risk assessment model was exercised to examine the effect of axle loads on the simulated occurrence rates of detected and service detects. Heavier average axle loads increase the bending stresses in the rail which increase the rate at which defects initiate and grow. Figure 6 shows the defect growth curves assumed for different average axle loads. As in the hypothetical example for rail size, these growth curves correspond to the fastest or left-most curve in Figure 2, which is used to account for seasonal influence on defect growth.

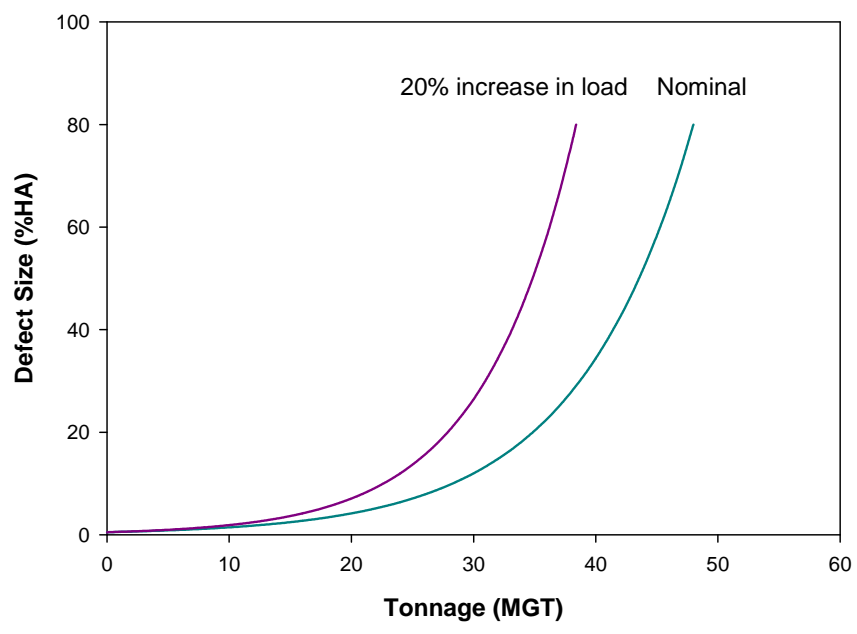

Figure 6: Defect Growth Curves for Different Average Axle Loads

In this hypothetical example, the traffic density for the nominal case is assumed to be 60 MGT per year. Heavier axle loads also mean a proportional increase in annual tonnage. Therefore, a 20 percent increase in average axle load translates to a traffic density of 72 MGT per year.

Axle loads have a significant influence on the rate of defect formation or the crack initiation life. The effect of axle load on defect formation is implemented into the Monte Carlo model through the characteristic life parameter $\beta$, defined in the Weibull distribution in equation (1). In the nominal axle loading case, $\beta$ is assumed to be equal to $1,500 \mathrm{MGT}$. For the heavier average axle load case, $\beta$ is equal to 1,250 MGT. $^{1}$

Figure 7 shows that the service defect rate for three rail tests per year under 20 percent increased average axle load is roughly equivalent to two rail tests per year under nominal axle load. The figure also shows that four rail tests per year under the heavier average axle load has a slightly greater risk of rail failure than three tests per year under the nominal axle load case. Moreover, the figure indicates that the heavier axle load case requires testing between four and six times per year in order to achieve an equivalent level of safety as three tests per year for the nominal load case. Therefore, the results shown in Figure 7 suggest that rail tests should be conducted at intervals between 12 to 18 MGT per rail if the average axle loads are increased by 20 percent, compared to an interval of 20 MGT per test for nominal axle loads.

\footnotetext{
${ }^{1}$ This value for $\beta$ is equal to 1,500 times 60 divided by 72 .
} 


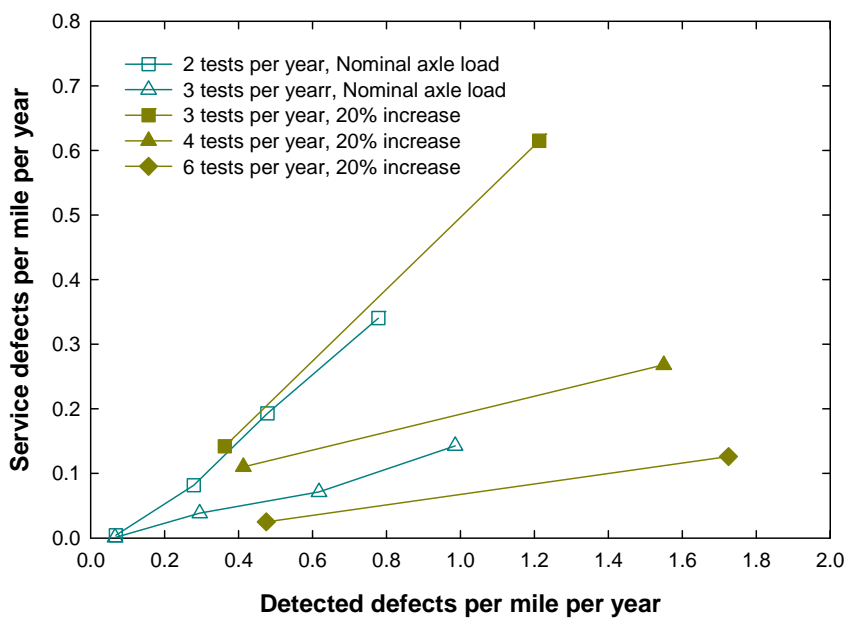

Figure 7: Effect of Axle Load and Inspection Frequency on Service Defect Rate

\section{High-Speed Rail Testing}

The risk assessment model can also be applied to examine other hypothetical situations. For example, one concept for allocating available resources is high-speed rail testing in which detector cars conduct rail tests to find defects at speeds greater than current practice (about 10 to 15 miles per hour). Faster speeds mean that more miles of track can be inspected within the limited amount of track time that may be available, but the trade-off may be reduced performance or reliability of the equipment in finding defects.

The concept of high-speed rail testing is examined using the risk assessment model by assuming that faster detector car speeds affect the reliability of finding defects and reduces the probability of detection. Figure 8 shows the probability of detection (POD) curves used in the model, which were developed assuming the following equation

$p(s)=k\left\{1-\exp \left[-\left(\frac{s-s_{0}}{s_{1}}\right)\right]\right\}$

where $k$ and $s_{1}$ are factors characterizing the reliability. In addition, the minimum detectable defect size is assumed to increase as the performance reliability is reduced. Table 1 lists the parameters assumed in equation (3) to produce the POD curves shown in Figure 8.

Table 1: Parameters for Assumed POD Curves

\begin{tabular}{ccc}
$k$ & $s_{0}(\% \mathrm{HA})$ & $s_{1}(\% \mathrm{HA})$ \\
\hline 1.0 & 5 & 14 \\
0.9 & 10 & 16 \\
0.8 & 15 & 18
\end{tabular}

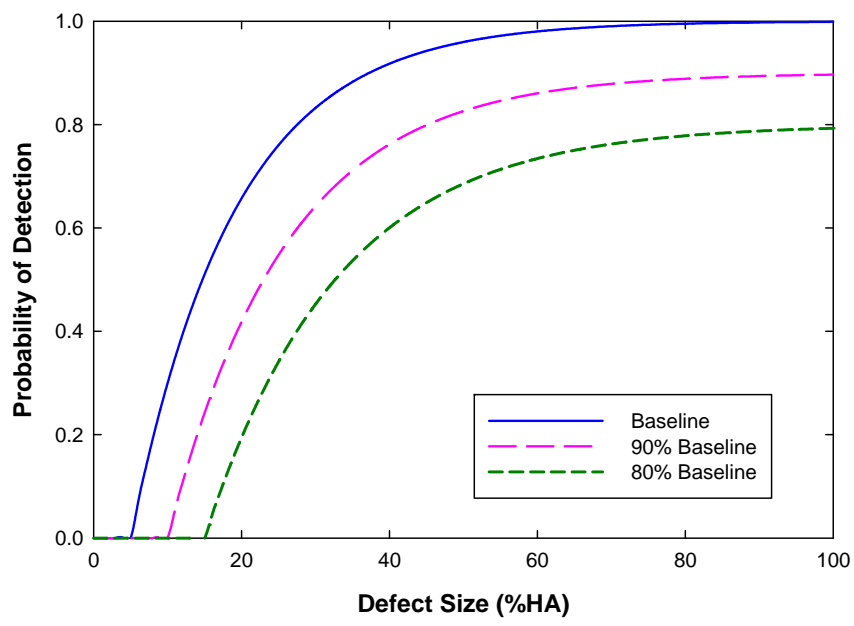

Figure 8: Probability of Detection Curves Assumed for Hypothetical High-Speed Rail Testing Scenarios

The risk assessment model is exercised for two levels of annual tonnage, 60 and 100 MGT per year, for the different levels of assumed reliability. For example, Figure 9 compares the detected and service defect rates for the baseline POD curve with those for the $90 \%$ reliability POD curve assumed in conducting rail inspections at higher speeds on a line carrying 60 MGT per year. The results for this hypothetical case suggest that four rail tests per year at high speed provides nearly the same level of safety as three rail tests per year at the current speed of the detector car. Figure 10 shows the model results if the reliability is lowered to 80 percent of the baseline. These results indicate that between five and six rail tests per year are needed to achieve the equivalent level of safety as three rail tests per year for the baseline POD curve.

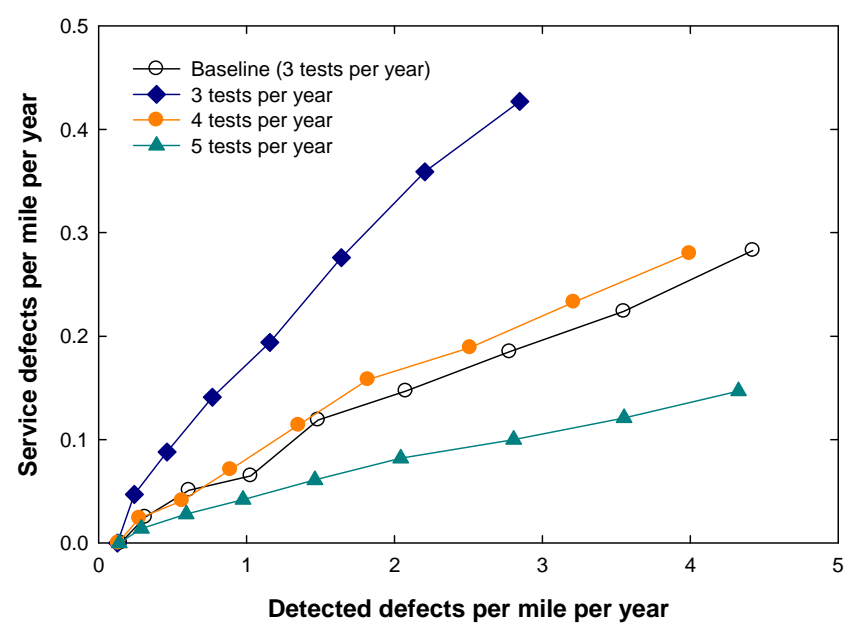

Figure 9: Defect Rates for 60 MGT per Year and 90 Percent Reliability of Baseline POD 


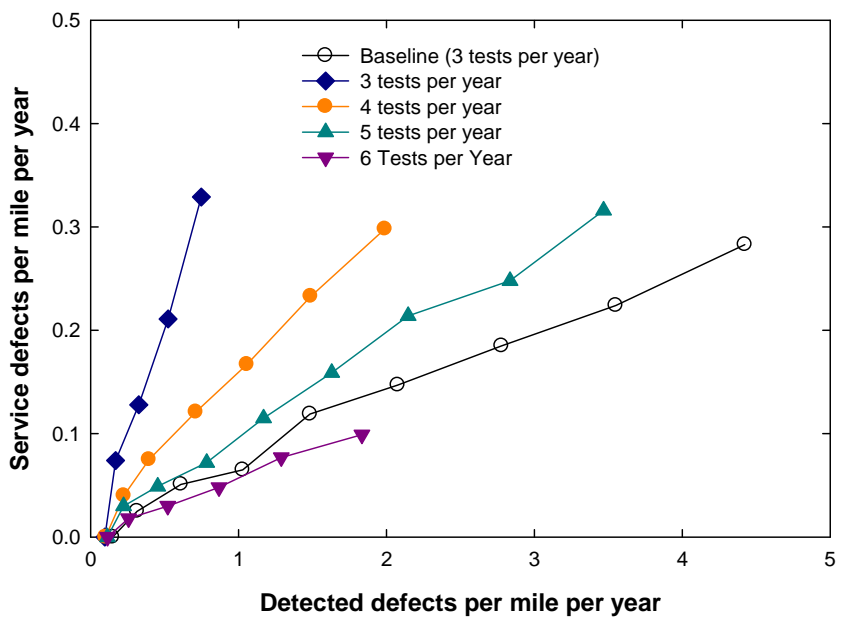

Figure 10: Defect Rates for 60 MGT per Year and 80 Percent Reliability of Baseline POD

Similarly, Figure 11 shows results for a higher tonnage line (100 MGT per year) and 90\% reliability of the baseline POD curve. In this hypothetical case, seven rail tests per year at high-speed rail testing provides the equivalent level of safety as five rail tests per year under current practice. Figure 12 shows model results for the higher tonnage line and 80\% reliability of the baseline POD curve. Here, the risk assessment model estimates that about ten rail tests per year under high-speed rail testing are required to achieve the same level of safety as five rail tests per year under current practice.

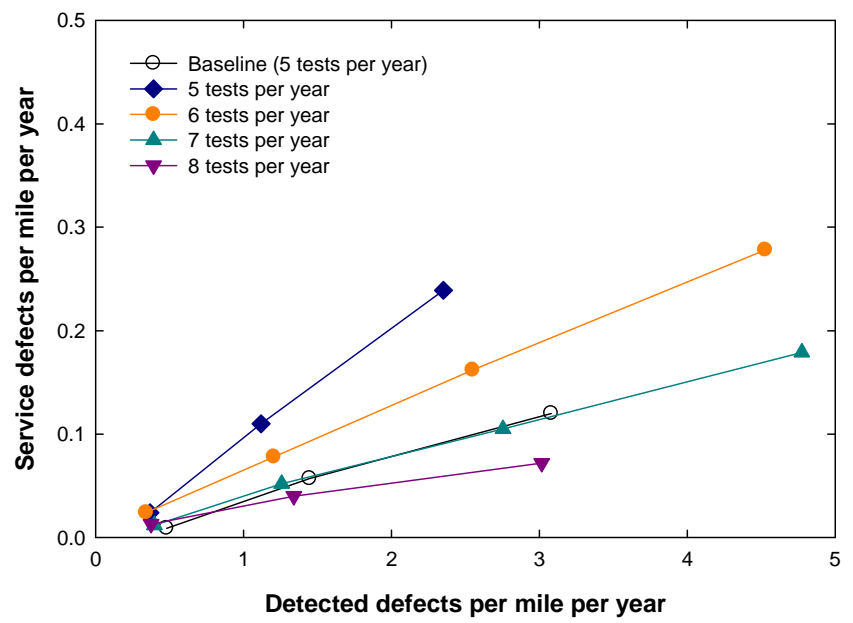

Figure 11: Defect Rates for 100 MGT per Year and 90 Percent Reliability of Baseline POD

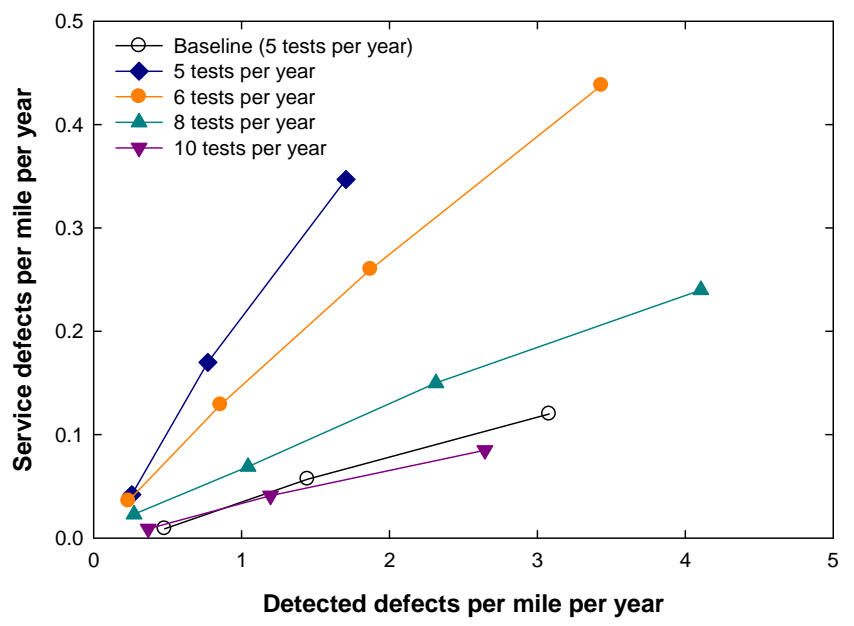

Figure 12: Defect Rates for 100 MGT per Year and 80 Percent Reliability of Baseline POD

\section{DISCUSSION}

Rail defect management is a continuous challenge for railroads because practical constraints exist. These constraints include limited availability of track time to conduct rail tests between running trains over the track and performing maintenance procedures and the fact that inspection technology is highly reliable but not perfect. Moreover, railroads must utilize available resources efficiently while providing a reasonable level of safety.

The application of engineering models to simulate defect formation, growth, detection and removal seems reasonable since the rail defects tend to form and grow at different rates on different lines or at different times on the same line. The Monte Carlo simulation approach addresses these differences in the initiation and propagation of internal rail defects.

The development of risk assessment tools allows for the systematic evaluation of hypothetical ("what if") scenarios and the potential benefits of alternative rail testing strategies. The concept of delayed remedial action was evaluated in previous work [3] using the risk assessment model. The concept of high-speed rail testing is evaluated in the present work. Assuming that higher detector car speeds reduces the probability of detection, an equivalent level of safety can be achieved by conducting rail tests more frequently. The risk assessment model can be used to determine how much more frequently to conduct such tests to ensure the same level of safety in terms of service defect occurrence rate.

Risk analysis may be applied to evaluate alternative concepts that may attempt to take advantage of known tendencies. For example, defects are known to initiate and grow faster in colder weather. This suggests that rail tests should be conducted more frequently during colder months. Risk modeling and analysis may be used to help determine effective scheduling of concentrated rail tests during colder months of the year. In addition, defects are known to form in 
clusters [11]. Modeling and analysis may be useful to concentrate rail testing in these areas where defects are prone to occur. Evaluation of potential strategies that account for the effects of cold weather and defect clustering are areas for future research.

Ultimately, the usefulness of risk modeling and analysis to evaluate rail testing strategies will be determined only when field experience is used to confirm and provide feedback into the modeling and analysis results.

While rail testing is the primary means to control defective rail, its effectiveness may be limited once the detected defect rate becomes excessively high (i.e., when occurrence of defects in the rails becomes widespread). At such a point in the life of the rail, its load bearing capacity may be exhausted and replacement of the rail with new rail may be the most effective strategy to maintain rail integrity.

\section{CONCLUDING REMARKS}

Railroad research has reached a point where risk analysis can be applied to help develop maintenance and inspection strategies to improve safety while also deploying resources efficiently. Risk modeling can be used to evaluate hypothetical scenarios compared to currently accepted practices.

A risk assessment model was described in this paper that simulates certain aspects of rail defect detection on a hypothetical railroad line. The model was exercised to examine the effect of changing operational factors on the rates of detected and service defects. Moreover, risk was quantified as the increase in service defects which are assumed to be directly related to the occurrence of rail failures or broken rails. The operational factors examined in this paper include rail size and average axle loading. In addition, the concept of high-speed rail testing was evaluated as alternative strategy for current practice. In this evaluation, reliability of detection equipment to find internal defects was assumed to be degraded as a consequence of conducting rail tests at higher than normal speeds. In each hypothetical case examined by the risk assessment model, an equivalent level of safety was achieved by varying the number of rail tests conducted on an annual basis.

The examples presented in this paper demonstrate how risk modeling and analysis can be applied to examine the effect of changing operational factors on the frequency of rail testing and the occurrence of service defects which may lead to rail failures or broken rails. Although a cost/benefit analysis was not included, these examples can provide the foundation for a more comprehensive risk analysis that may consider the economic consequences associated with broken rails.

\section{ACKNOWLEDGMENTS}

The work reported in this paper was carried out under the Rail Integrity program sponsored by the Office of Research and Development, Federal Railroad Administration, U.S.
Department of Transportation, under the direction of Mr. Gary Carr, Chief of the Track Research Division. Mr. Ali Tajaddini is the Project Manager for the research related to rail integrity.

\section{REFERENCES}

[1] Orringer, O., Tang, Y.H., Gordon, J.E., Jeong, D.Y., Morris, J.M., Perlman, A.B., "Crack Propagation Life of Detail Fractures in Rails,” Volpe Center Final Report, DOT/FRA/ORD-88/13, October 1988.

[2] Orringer, O., "Control of Rail Integrity by Self-Adaptive Scheduling of Rail Tests," Volpe Center Final Report, DOT/FRA/ORD-90/05, October 1988.

[3] Orringer, O., Tang, Y.H., Jeong, D.Y., Perlman, A.B., "Risk/Benefit Assessment of Delayed Action Concept for Rail Inspection," Volpe Center Final Report, DOT/FRA/ORD-99/03, April 1999.

[4] Besuner, P.M., Stone, D.H., DeHerrera, M.A., Schoeneberg, K.W., "Statistical Analysis of Rail Defect Data (Rail Analysis - Volume 3),” AAR Chicago Technical Center, Report Number R-302, 1978.

[5] Weibull, W., "A Statistical Distribution Function of Wide Applicability," Journal of Applied Mechanics, Transactions of the American Society of Mechanical Engineers, pp. 293-297, 1951.

[6] Orringer, O., Morris, J.M., Steele, R.K., “Applied research on rail fatigue and fracture in the United States," Theoretical and Applied Fracture Mechanics 1, 1984.

[7] Orringer, O., Morris, J.M., Jeong, D.Y., "Detail fracture growth in rails: test results," Theoretical and Applied Fracture Mechanics 5, 1986.

[8] Clayton, P., and Tang, Y.H., "Detail fracture growth rates in curved track at the Facility for Accelerated Service Testing," Residual Stress in Rails: Effects on Rail Integrity and Railroad Economics - Volume 1: Field Experience and Test Results, edited by O. Orringer, J. Orkisz, and Z. Swiderski, Dordrecht, The Netherlands, Kluwer Academic Publishers, 1992

[9] Jeong, D.Y., "Correlations Between Rail Defect Growth Data and Engineering Analyses, Part I: Laboratory Tests," Volpe National Transportation Systems Center, Cambridge, MA, in support of the UIC World Executive Council Joint Research Project on Rail Defect Management, May 2003.

[10] Jeong, D.Y., "Correlations Between Rail Defect Growth Data and Engineering Analyses, Part II: Field Tests," Volpe National Transportation Systems Center, Cambridge, MA, in support of the UIC World Executive Council Joint Research Project on Rail Defect Management, January 2003.

[11] Orringer, O., Bush, M.W., “Applying modern fracture mechanics to improve the control of rail fatigue defects in track," American Railway Engineering Association Bulletin 689, Volume 85, 1983. 